\title{
Nuevos marcadores en las biopsias de próstata
}

\author{
Molinié $\mathrm{V}^{*}$, Baumert $\mathrm{H}^{* *}$. \\ *Department of Pathology. **Department of Urology. Hôpital Saint-Joseph, Paris, France.
}

Actas Urol Esp. 2007;31(9):1009-1024

\begin{abstract}
NUEVOS MARCADORES EN LAS BIOPSIAS DE PRÓSTATA

El cribado mediante la determinación del antígeno específico prostático (PSA) como estrategia para la detección precoz del cáncer de próstata ha dado lugar a un aumento dramático en el número de cilindros de biopsia que los anatomopatólogos tienen que examinar. De modo paralelo, se ha producido un importante aumento en el número de diagnósticos de lesiones ambiguas, lo que dificulta la emisión de un informe inequívoco de malignidad, de modo particular en los casos donde se identifican focos limitados o lesiones acinares atípicas de pequeño tamaño. Cuando se valoran focos de pequeño tamaño o glándulas atípicas a partir de especímenes de biopsia, el anatomopatólogo trata de identificar diferencias entre las glándulas benignas y las glándulas atípicas en términos de rasgos morfológicos habituales; en esos casos, la identificación de inmunoreactividad para marcadores de células basales tales como el anticuerpo $34 \beta \mathrm{E} 12$ o los anticuerpos contra la citoqueratina 5 y 6 y, más recientemente, el p63, pueden representar ayudas útiles para identificar células basales típicamente presentes en las glándulas benignas pero ausentes en el carcinoma de próstata.

Sin embargo, algunas lesiones benignas que remedan al carcinoma de próstata (incluyendo la atrofia, la hiperplasia adenomatosa atípica y el adenoma nefrogénico) pueden no teñirse con esos anticuerpos; en consecuencia, una tinción negativa aislada para marcadores de células basales no excluye un diagnóstico de benignidad. En estas circunstancias, un nuevo marcador para cáncer de próstata podría ser útil para la confirmación de lesiones ambiguas sospechosas de malignidad. De cualquier manera, y de modo similar a lo que sucede con otros estudios inmunohistoquímicos, existen problemas de sensibilidad y especificidad. El objetivo de esta revision es describir los rasgos histológicos del cáncer de próstata en pequeños focos, y discutir la aplicación de estos nuevos marcadores prostáticos a la luz de la literatura científica mas reciente para destacar las mejores guias prácticas.

Palabras clave: Cáncer de próstata. AMACR/p504s. Racemasa. Cáncer de próstata mínimo. ASAP. Inmunotinción. p63.
\end{abstract}

\section{ABSTRACT \\ NEW MARKERS IN PROSTATE BIOPSIES}

The use of serum prostate-specific antigen screening to facilitate early detection of prostate cancer has resulted in a dramatic increase in the number of prostate needle core biopsies which pathologists must examine. This has been accompanied by a strong increase in the number of biopsies with ambiguous lesions, and an unequivocal diagnosis of malignancy is difficult to render, especially in the case of limited foci or in small atypical acinar lesions. When assessing small foci of atypical glands upon needle biopsy, the pathologist searches for differences between the benign glands and atypical glands in terms of usual morphological features and in such cases, immunohistochemical stains for basal cell markers such as $34 \beta \mathrm{E} 12$ antibody or antibodies directed against cytokeratin 5 and 6 and more recently p63 may be a useful adjuvant to identify basal cells which are typically present in benign glands but absent in prostatic carcinoma. However several benign mimickers of prostate carcinoma, including atrophy, atypical adenomatous hyperplasia, nephrogenic adenoma can stain negatively with these antibodies and thus a negative basal cell marker immunostain alone does not exclude a diagnosis of benignancy. Alphamethyl-coenzyme-A-racemase (AMACR) a new sensitive marker of prostate carcinoma, can be useful in confirming ambiguous lesion suspected for malignancy. Although, as with any immunohistochemical studies, problems exist in terms of both sensitivity and specificity. The aim of this review is to describe the histological features of prostatic carcinoma in case of small focus, and discuss the application of these new prostatic markers in the light of the current literature to highlight the best practice guidelines.

Keywords: Prostate cancer. AMACR/p504s. Racemase. Minimal prostate cancer. ASAP. Immunostaining. p63. 
$\mathrm{E}$ cribado mediante la determinación del antígeno específico prostático (PSA) como estrategia para la detección precoz del cáncer de próstata ha dado lugar a un aumento dramático en el número de cilindros de biopsia que los anatomopatólogos tienen que examinar. De modo paralelo, se ha producido un aumento muy importante en el número de biopsias con lesiones ambíguas, tales como proliferaciones acinares atípicas de pequeño tamaño sospechosas de cáncer pero no diagnósticas (ASAP), y microfocos de adenocarcinoma, definidas como focos únicos de un tumor menor de $1 \mathrm{~mm}$ en su dimensión mayor.

El diagnóstico de adenocarcinoma de próstata en la biopsia de próstata depende de la identificación de una serie de criterios histológicos en preparaciones teñidas con hematoxilinaeosina $^{1}$. A partir del mero examen de esas preparaciones es difícil proporcionar un diagnóstico inequívoco de malignidad, especialmente en el caso de focos limitados o en el caso de lesiones acinares atípicas de pequeño tamaño. Cuando se estudian pequeños focos de glándulas atípicas en muestras de biopsia, el patólogo trata de identificar las diferencias entre las glándulas benignas y las glándulas atípicas en sus rasgos nucleares, citoplásmicos, y contenidos intraluminales ${ }^{1}$. En esos casos, la tinción inmunohistoquímica para queratinas de alto peso molecular tales como la 34 betaE 12 y, más recientemente, el CK 5/6 o el p63, puede resultar de utilidad para identificar células basales típicamente presentes en las glándulas benignas pero ausentes en el carcinoma de prósta$\mathrm{ta}^{2,3}$. De cualquier manera, y de modo similar a lo que sucede con otros estudios inmunohistoquímicos, existen problemas de sensibilidad y especificidad $^{4}$. El objetivo de esta revisión es describir los rasgos histológicos del carcinoma de próstata en pequeños focos, y discutir la aplicación de marcadores prostáticos a la luz de la literatura más reciente para destacar las mejores guías prácticas.

\section{INTERPRETACIÓN DE LESIONES AMBÍGUAS}

Las lesiones ambiguas representan un desafio importante para los anatomopatólogos que deben distinguir con precisión las glándulas prostáticas benignas de las malignas. Numerosas proliferaciones glandulares benignas de pequeño tamaño pueden remedar el cáncer de próstata, particularmente en las biopsias con aguja, donde la arquitectura general de la lesión puede no ser reconocida inmediatamente ${ }^{5}$. El diagnóstico de pequeños focos de carcinoma en especímenes de biopsia se basa en la identificación de una constelación de rasgos que se presentan con mayor frecuencia en los carcinomas ${ }^{1}$. Los criterios histológicos mayores para el diagnóstico de carcinoma de próstata son los siguientes: (1) acinos que infiltran el estroma prostático, particularmente entre las glándulas benignas, (2) atipia nuclear, asociada o no a macronucleolos prominentes, (3) citoplasma basófilo, (4) contenido intraluminal del tipo de cristaloides (Fig. 1) o necrosis eosinófila, y (5) ausencia de la capa de células basales ${ }^{1}$.

En la mayoría de los casos, el diagnóstico de adenocarcinoma mínimo es posible a partir de la utilización de esos criterios $^{6}$.Únicamente un número limitado de rasgos -tales como las glomerulaciones, la fibroplasia mucinosa (micronódulos de colágeno) y la invasión perineural- son patognomónicos de cáncer de próstata ${ }^{1,4}$ (Fig. 2). Sin embargo, existen circunstancias en las cuales los rasgos morfológicos son insuficientes para alcanzar un diagnóstico de certeza de malignidad, lo que hace obligada la confirmación de la sospecha mediante la identificación de marcadores

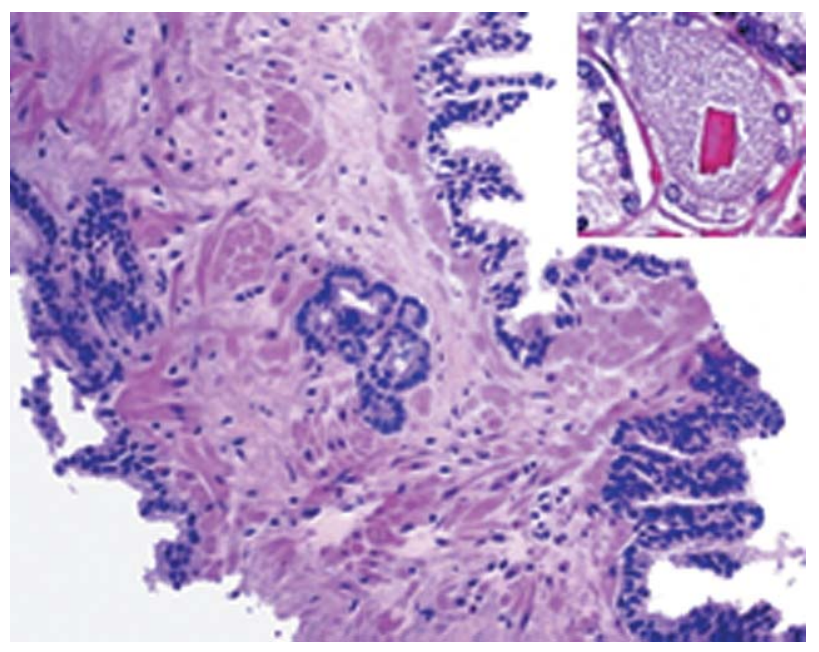

FIGURA 1. Criterios histológicos de carcinoma de próstata: infiltración de las glándulas prostáticas; recuadro superior derecho: cristaloide. 


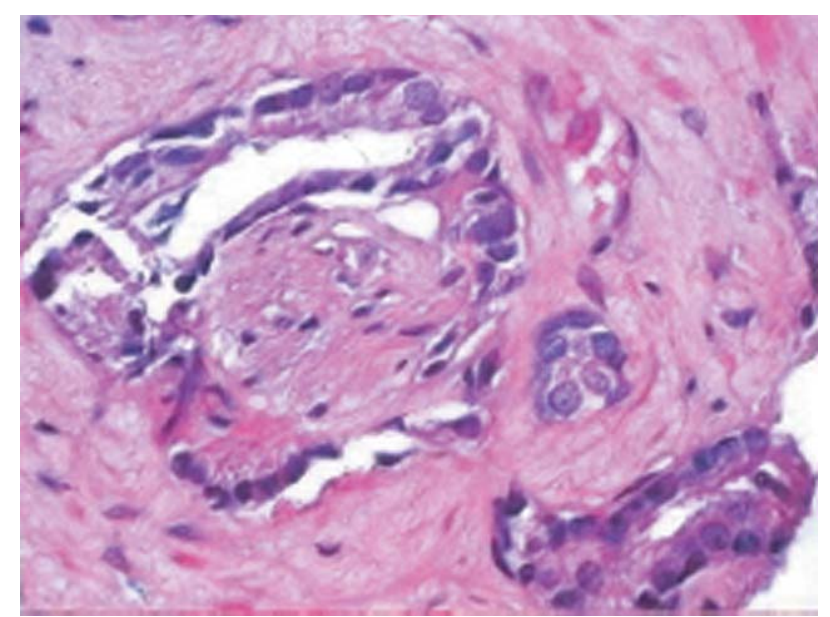

FIGURA 2. Criterios histológicos específicos de carcinoma de próstata: invasión perineural.

celulares basales. La inmunohistoquímica puede resultar un método diagnóstico complementario para el estudio de focos limitados de carcinoma de próstata. Un rasgo distintivo de las entidades benignas que remedan a los cánceres de próstata, es la presencia de células basales, ausentes en las glándulas cancerosas, tal y como fue descrito por Totten et al. en 19537. Sin embargo, la diferenciación morfológica de las células basales de los fibroblastos estromales es frecuentemente dificultosa; además, las células basales pueden pasar inadvertidas en algunas glándulas benignas, lo que obliga al anatomopatólogo a utilizar marcadores inmunohistoquímicos para identificarlas $^{1,8,9-11}$ (Tabla 1).

\section{MARCADORES DE CÉLULAS BASALES CITOQUERATINAS}

Los marcadores de células basales, tales como la citoqueratina (CK) de alto peso molecular 903 (34ßE12), la CK 5/6, y el p63, subrayan la presencia de células basales en las glándulas benignas. Esas células se hayan ausentes en los carcinomas de próstata ${ }^{12}$. Tras los primeros resultados de la utilización de la CK 903 como marcador de células basales prostáticas (Gown and Vogel, 1984) ${ }^{13}$, numerosos estudios han demostrado que la aplicación sistemática de anticuerpos frente a las CK de alto peso molecular (high-molecular-weight cytokeratins, HMWCK) resulta particularmente útil para la identificación de las células basales, y aplicable en la rutina (Fig. 3). El anticuerpo frente a la CK 903 conduce a la con-

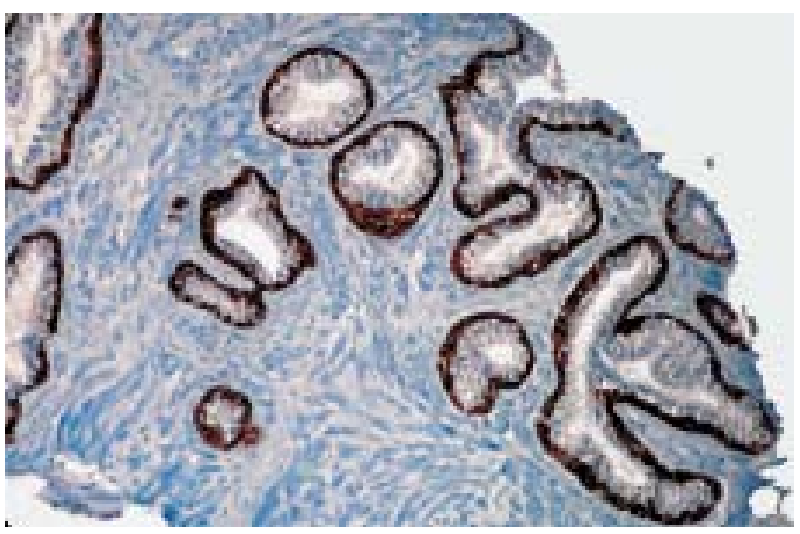

FIGURA 3. 34ßE12 (CK 903) en glándulas normales: inmunotinción de las células basales.

Tabla 1. Anticuerpos utilizados con mayor frecuencia en el estudio de focos sospechosos en biopsias de próstata.

\begin{tabular}{|c|c|c|c|}
\hline Anticuerpo & Antigeno & Patrón de tinción & Diana \\
\hline $34 \beta \mathrm{E} 12$ & Citoqueratina $1,5,10$ y 14 & Citoplásmico y membranoso & Células basales \\
\hline CK 5/6 & Citoqueratinas 5 y 6 & Citoplásmico y membranoso & Células basales \\
\hline p63 & Proteína nuclear p63 & Nuclear & Células basales \\
\hline p63/34 $\beta E 12$ & $\begin{array}{l}\text { Proteína nuclear p63 } \\
\text { Citoqueratina } 1,5,10 \text { y } 14\end{array}$ & $\begin{array}{l}\text { Nuclear } \\
\text { Citoplásmico y membranoso }\end{array}$ & Células basales \\
\hline AMACR (p504s) & $\alpha$-metilacil-Co-A-racemasa & $\begin{array}{l}\text { Granular circunferencial } \\
\text { Tinción intracitoplásmica } \\
\text { Difusa o apical }\end{array}$ & $\begin{array}{l}\text { Carcinoma de próstata } \\
\text { PIN de alto grado } \\
\text { Hiperplasia adenomatosa atípica } \\
\text { Glándulas normales }\end{array}$ \\
\hline PIN cocktail & $\begin{array}{l}\text { Combinación de p63 } \\
\text { y AMACR }\end{array}$ & $\begin{array}{l}\text { Combinación de tinción de } \\
\text { p63 y AMACR }\end{array}$ & Células basales y malignas \\
\hline
\end{tabular}


firmación histológica en el 58\% de los casos; de modo similar, proporciona un resultado correcto en el $18 \%$ de los casos dudosos, y modifica el diagnóstico histológico en el $2 \%$ de las ocasiones $^{4,14,15}$. Sin embargo, este anticuerpo no es de utilidad práctica en el $8 \%$ de $\operatorname{los} \operatorname{casos}^{16}$. Además, no todas las glándulas benignas se tiñen de modo uniforme con marcadores de las células basales. A esa limitación hay que añadir que el estrato celular desaparece en el $11 \%$ de los casos de atrofia, en el $12 \%$ de los casos de hiperplasia de células basales y en 10-90\% de los casos de hiperplasia adenomatosa atípica ${ }^{4}$. La tinción puede resultar aún menos uniforme en algunas de las lesiones que remedan a los carcinomas prostáticos. En consecuencia, una tinción negativa para marcadores de células basales en un pequeño foco de glándulas atípicas no es diagnóstica de adenocarcinoma de próstata. Un patrón de inmunoreactividad HMWCK en las células basales de glándulas sospechosas casi siempre excluye un diagnóstico de cáncer de próstata, tal y como ha sido recogido en varios estudios independientes donde se ha establecido que los cánceres de próstata muy raramente expresan HMWCK. Yang et al. han detectado positividad a $34 \beta E 12$ únicamente en el $2 \%$ de los cánceres de próstata metastáticos; en esos casos la inmunorreactividad se encontró restringida a un tipo raro de células con morfología de células tumorales de alto grado, en lugar de detectarse en las células basales ${ }^{17}$.

En relación a los otros anticuerpos frente a CK, existen evidencias de que el CK 5/6 representa un marcador de células basales muy sensible y específico; los resultados insatisfactorios han sido $\operatorname{limitados}^{18}$. El CK 5/6, expresado normalmente por el epitelio complejo, es un marcador de las células mesoteliales y del mesotelioma maligno, y de los carcinomas de páncreas, tracto biliar y de mama ${ }^{12,19,20}$. Ese anticuerpo reacciona con las células basales prostáticas (Fig. 4), pero no lo hace con las celulas tumorales prostáticas ni con las neoplasias intraepiteliales prostáticas (prostate intraepithelial neoplasia, PIN), con independencia del momento en que tenga lugar la determinación y el tipo de fijador utilizado para la conservación de la pieza (formol o solución de Bouin) ${ }^{19,20}$. El CK 5/6 no precisa de restauración

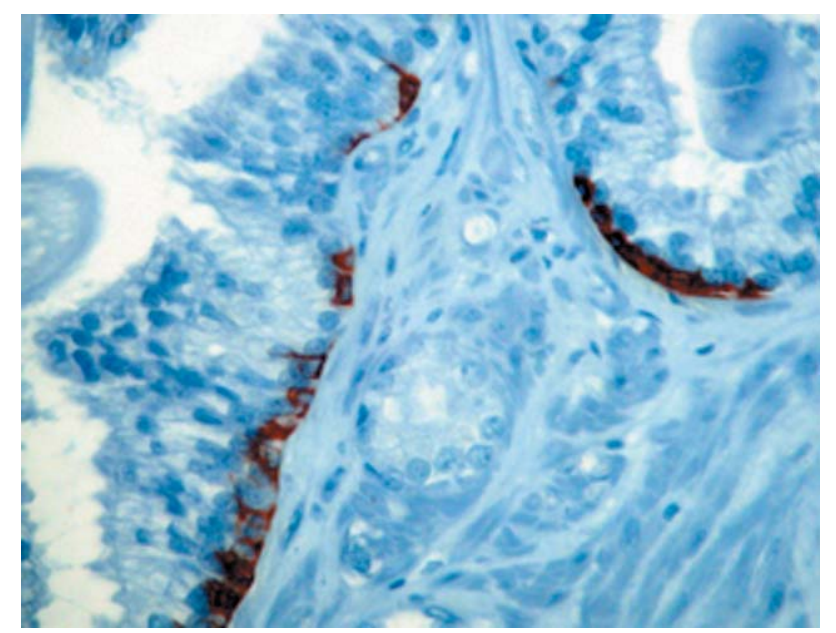

FIGURA 4. Pequeño foco de carcinoma: ausencia de tinción de células basales con CK5/6 en glándula carcinomatosa. Presencia de tinción citoplásmica CK 5/6 en células basales normales.

antigénica compleja, y está dotado de una sensibilidad del 97-100\% y de una especificidad del $62 \%$, superior al $40 \%$ que se obtiene con la utilización del CK $903^{18}$. En nuestra experiencia, en el caso de lesiones ambiguas, el CK 5/6 es más efectivo que el CK $903^{21,22}$.

Existe experiencia en la utilización de anticuerpos contra CK. En el Reino Unido se ha ensayado LP34 frente a CK5 / CK6 y CK18. Como resultado de su reactividad frente a CK18, el LP34 ha sido identificado también en las células luminales, aunque su presencia a ese nivel es más restringida que en las células basales, lo que añade dificultad a la interpretación de la inmunotinción ${ }^{23}$.

\section{NUEVOS MARCADORES DE CÉLULAS BASALES}

El p63 es un nuevo marcador específico de células basales que ha sido ensayado recientemente. La proteína p63, que comparte homología con el gen supresor tumoral p53, parece desempeñar un papel crítico como regulador del crecimiento y del desarrollo del epitelio cutáneo, del cuello uterino, del tracto genital y de la mama y, de modo particular, del desarrollo prostático ${ }^{24}$. Signoretti et al. individualizaron por primera vez la isoforma $\Delta \mathrm{Np} 63$ en las células basales prostáticas, y demostraron el papel determinante del p63 en el desarrollo de la próstata ${ }^{25}$. Por primera vez, pusieron de manifiesto que la expresión 
inmunohistoquímica de p63 en los acini prostáticos se limitaba a las células basales con un patrón de inmunorreactividad nuclear, mientras que las células secretoras benignas y los cánceres de próstata resultaron consistentemente negativos para $\mathrm{p} 63^{25}$. Posteriormente, numerosos estudiosos han confirmado la expresión de p63 en las células basales de las glándulas prostáticas normales ${ }^{8,10,26}$; de modo similar, ha quedado demostrado que la gran mayoría de los cánceres de próstata (89-94\%) no expresan $163^{10}$, y que la inmunotinción para p63 representa un novedoso método auxiliar para facilitar el diagnóstico de cáncer de próstata en biopsias por aguja ${ }^{27}$. Otros estudios indican que las células tumorales prostáticas no expresan p63, por lo que puede utilizarse en el mismo sentido que el CK 903 para el análisis de las pequeñas proliferaciones acinares atípicas sospechosas (pero de aspecto histológico no diagnóstico) de malignidad ${ }^{28}$ (Fig. 5).

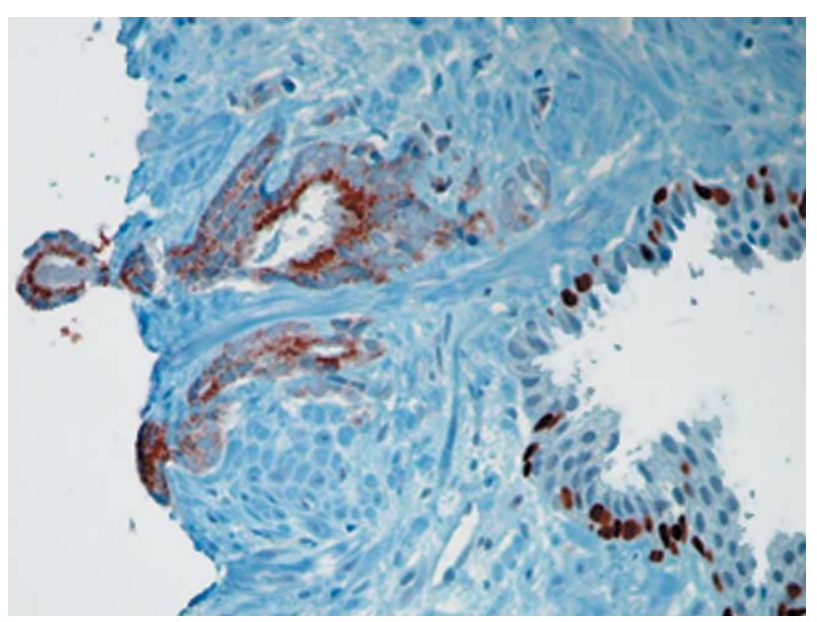

FIGURA 5. p63/p504s en pequeño foco de carcinoma: positividad granular citoplásmica apical de las glándulas neoplásicas con p504s (izquierda) y ausencia de células basales. Derecha: glándula normal con positividad p63 nuclear en las células basales.

\section{COMPARACIÓN DE LOS MARCADORES DE CÉLULAS BASALES}

Unos pocos estudios han intentado comparar la utilidad del p63 y de otros marcadores de células basales tales como CK5/6, CK14, 34ßE12 y LP34. Según Abrahams et al. el CK5/6 es significativamente superior al $34 \beta \mathrm{E} 12^{18}$. Freeman et al. compararon preparaciones teñidas con LP34, CK5/6 y CK14; la inmunotinción con LP34 fue la más útil para la distinción entre el adenocarcinoma de próstata y el PIN, en tanto que CK5/6 resultó mejor para la distinción entre el adenocarcinoma de próstata y la atrofia lobular ${ }^{2}$. Shah et al. compararon la utilidad de las inmunotinciones con p63 y $34 \beta \mathrm{E} 12$ en el estudio de casos particularmente desafiantes desde el punto de vista diagnóstico, y concedieron una ligera superioridad al p63, especialmente en para el estudio de muestras de resección transuretral de próstata (RTUP) ${ }^{11}$. En la experiencia de Weinstein et al. el rendimiento del p63 resultó superponible al de $34 \beta \mathrm{E} 12$, al tiempo que comprobaron una mejor preservación de la antigenicidad del p63 en las áreas artefactadas por cauterio en muestras de RTUP $^{26}$. De modo similar a lo comunicado por Zhou et al., nuestra propia experiencia reveló una total ausencia de células basales tras la tinción de muestras de cáncer de próstata con p63; su sensibilidad y especificidad resultaron superiores a las observadas tras la utilización de CK $5 / 6^{22,27,29}$.

En resumen, existen al menos tres marcadores útiles para Ia tinción de las células basales (CK903, CK5/6 y p63), cuya presencia es considerada como 'negativa' desde el punto de vista diagnóstico, en el sentido de que su presencia en focos atípicos acinares de pequeño tamaño excluye el cáncer de próstata. Sin embargo, esos marcadores no son completamente sensibles para la detección de las células basales; además, y como ya se ha mencionado, en algunos casos raros de cáncer de próstata se ha demostrado la presencia de tinción focal con CK903. Desde el momento en que el diagnóstico de cáncer de próstata mediante marcadores de células basales se sustenta en la ausencia uniforme de inmunorreactividad en las células cancerosas, existe siempre un pequeño riesgo de reacción falsamente negativa debida a una variedad de factores técnicos. A pesar de la aplicación de nuevos métodos para la realización de las técnicas inmunohistoquímicas -incluyendo la utilización de equipos de inmunotinción automática (Ventana, Dako), y de la automatización de la restauración antigénica térmica-, estos anticuerpos son de dificil uso, especialmente cuando el tejido ha sido fijado en líquido de Bouin que requiere algunas sutilezas para la restauración antigénica tales como la digestión de 
las proteasas, la recuperación térmica, la aplicación de sistemas de revelado y, en ocasiones, la suma de los tres procedimientos ${ }^{23}$.

\section{MARCADORES DE CÁNCER DE PRÓSTATA P504s/AMACR}

Desgraciadamente, una tinción negativa para células basales en unas pocas células sospechosas no es una prueba definitiva de malignidad, dado que algunas entidades benignas pueden exhibir una distribución de células basales parcheada o discontinua ${ }^{23}$. Por ese motivo, un marcador 'positivo' específico para carcinoma de próstata resultaría muy útil para mejorar el nivel de fiabilidad del diagnóstico. Existe un considerable interés en el desarrollo de inmunomarcadores de adenocarcinoma de próstata mediante la tinción específica de las células malignas propiamente dichas. Por esas razones, la identificación del marcador de cáncer de próstata a-metilacilCo A racemasa (AMACR) constituye una aportación verdaderamente afortunada ${ }^{30}$. La AMACR es una enzima de 382 aminoácidos, purificada y caracterizada en 1995 en el curso del estudio del metabolismo lipídico tisular en humanos $^{2,14,21,27,30-39}$. Ferdinanduse et al. demostraron que la AMACR participa en la beta oxidación de ácidos grasos de cadena ramificada y de derivados de ácidos gra$\operatorname{sos}^{2}$. En el año 2000, Xu et al. identificaron tres genes mediante la técnica de sustracción de cDNA sumada al screening de microarray de cDNA de alto rendimiento: los genes P503s, P504s y P501s se expresan de modo diferente en tejido prostático maligno y benigno. $\mathrm{El}$ gen P504s fue claramente identificado como una AMACR humana ${ }^{40}$. La AMACR aislada y su RNA mensajero (p504s) aparecieron sobreexpresados en la mayoría de carcinomas de próstata. Adicionalmente, $\mathrm{Xu}$ et al. generaron anticuerpos monoclonales de conejo específicos, y demostraron la presencia de inmunorreactividad frente a P504s en el carcinoma de próstata.
Mediante la técnica de Western-blot se observó una sobreexpresión de p504s en carcinomas en comparación con el tejido glandular benigno (36 veces superior) ${ }^{40}$. Empleando un anticuerpo altamente específico (p504s) frente a la enzima, Jiang et al. comprobaron que la poderosa inmunotinción de la enzima se encontraba consistentemente presente en el carcinoma de próstata y en el PIN de alto grado procedente de la zona periférica de la próstata ${ }^{31}$. En contraste, no se detectó inmunotinción en el $88 \%$ de 173 casos con hiperplasia hipertrófica benigna, en tanto sólo se detectó inmunotinción débil y de distribución focal $^{31}$ en el $12 \%$ restante (Fig. 6). La conclusión de los investigadores fue que el p504s es un marcador para el carcinoma de próstata altamente sensible y específico. A lo largo de los últimos cuatro años, muchos estudios han detectado una sobrerregulación de AMACR a nivel proteico y trancripcional en PIN de alto grado y en cáncer de próstata $^{9,34,41}$. Los estudios iniciales sugirieron positividad intensa y uniforme de AMACR en el 97-100\% de los cánceres de próstata ${ }^{34,35}$. Estudios posteriores confirmaron que la AMACR tiñe el citoplasma de aproximadamente el 80\% de los carcinomas de próstata en biopsias por aguja ${ }^{6,21,22,38}$, y que en los casos positivos no

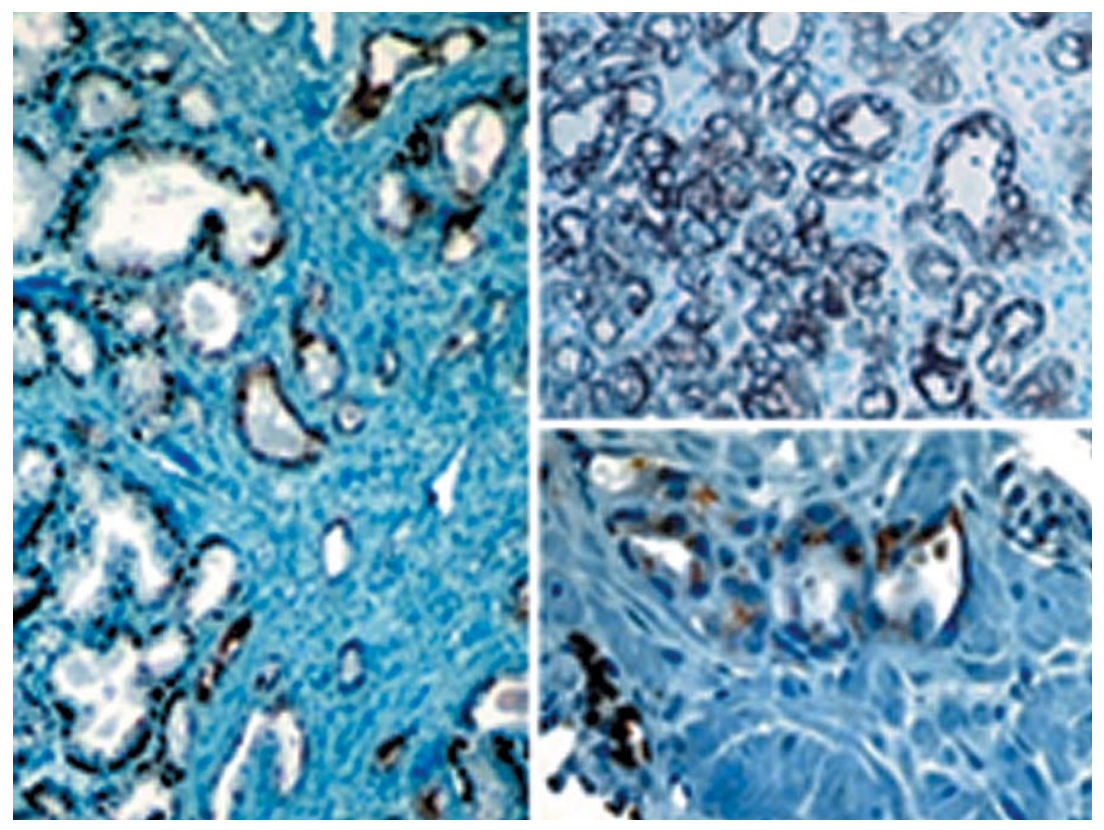

FIGURA 6. Expresión de p63/p504s en la hiperplasia adenomatosa atipica (izquierda), metaplasia nefrogénica (derecha, arriba) y lesiones ambiguas (derecha, abajo). 
todas las glándulas tumorales resultan positivas, además, a menudo, la tinción no es intensamente positiva. Ciertas variantes histológicas, como las de glándulas espumosas y los carcinomas atróficos y pseudohiperplásicos, resultaron incluso menos frecuentemente positivos para AMACR (positividad limitada al 60-80\% de los casos) ${ }^{39}$

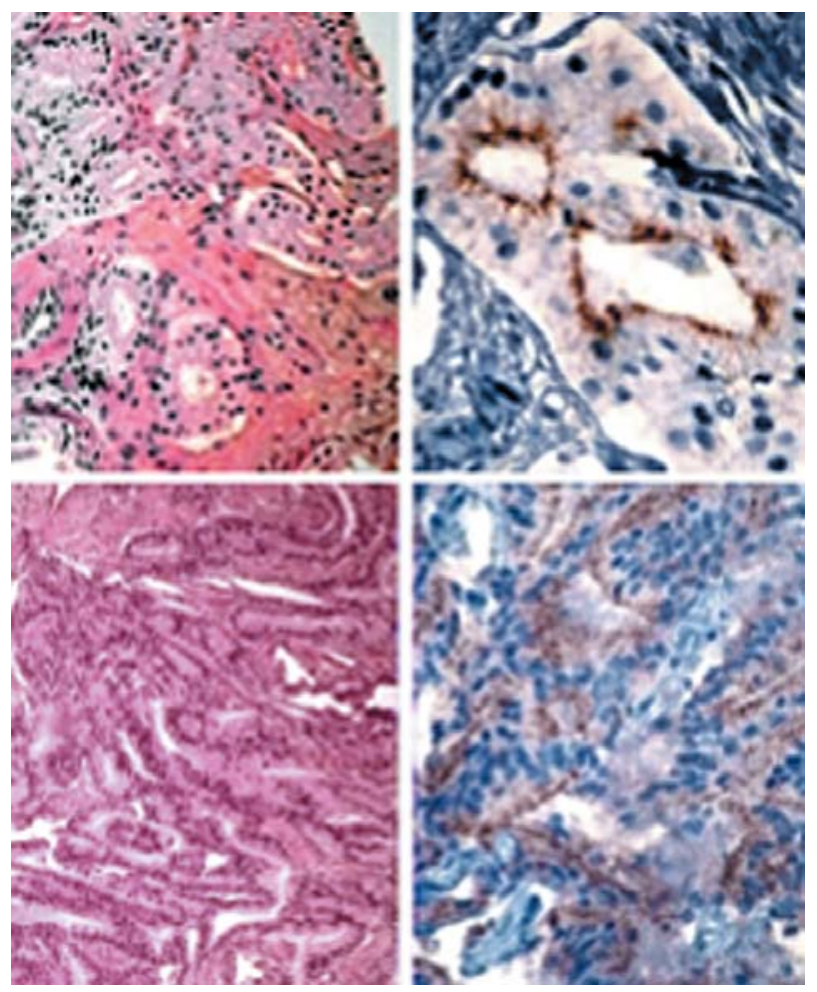

FIGURA 7. P63/P504S en el carcinoma de próstata: carcinoma de células espumosas (arriba); carcinoma intraductal (abajo).

(Fig. 7). Más recientemente, Schostak et al. demostraron la utilidad de la detección mediante PCR cuantitativa de tránscritos de RNA de AMACR en tejido prostático, como alternativa al estudio inmunohistoquímico, especialmente en presencia de especímenes minúsculos procedentes de biopsia por aguja ${ }^{42}$. En nuestra experiencia, la positividad para p504s se observó en el 97\% de los cánceres de próstata, con independencia de la suma de Gleason $(\mathrm{p}=0,29)$, y de la técnica de fijación $(\mathrm{p}=0,27)$. La sensibilidad fue superior para la combinación de p504s y p63 (95\%) en comparación con CK5/6 (57\%) y p63 (86\%). De modo similar, la especificidad fue superior para la combinación p504s/p63 (95\%) en comparación con CK5/6 (88\%) y p63 (81\%) ${ }^{28,34}$. La implicación práctica de estos hallazgos es que la tinción con AMACR debería ser interpretada con cautela. Cuando consideramos la intensidad de la inmunotinción con p504s, encontramos tinción citoplásmica moderada-intensa únicamente en el $67 \%$ de los casos, y débil en el 31\% de nuestros $\operatorname{casos}^{27}$. Estos hallazgos podrían explicar nuestros mejores resultados en inmunotinción en comparación con el 80-85\% de expresión de p503s habitualmente comunicada en el cáncer de próstata. La sensibilidad de la AMACR en la detección de cáncer de próstata en los estudios publicados ${ }^{14,21,30-}$ $35,38,39,41,43-46$ aparece resumida en la Tabla 2. De modo similar a Zhou et al. y Herawi et al., nosotros consideramos que una tinción negativa para AMACR no debería propiciar la sustitución de un diagnóstico de cáncer de próstata basado en la interpretación de secciones de hematoxilina-eosina, por otro de 'atipia', ni transformaria un diagnóstico de 'atipia' en un diagnóstico de benigni$\operatorname{dad}^{37,38,47,48}$.

Además de sus problemas de sensibilidad, la AMACR todavía se considera como no enteramente específica para adenocarcinoma, dado que teñirá casi todos los casos de PIN de alto grado, algunos focos de adenosis, la atrofia parcial, los focos de microacinos agrupados, e incluso algunas glándulas benignas ${ }^{47}$. En $20-99 \%$ de los casos de PIN de alto grado, las células expresaron p504s, con un patrón intracitoplásmico granular, y con una intensidad de tinción más débil para P504s en el PIN de alto grado en comparación con los carcinomas de próstata 22,41,49 (Fig. 8).

Varios estudios han comunicado que el p504s puede ser positivo en 21-36,4\% de las glándulas normales ${ }^{38,41}$. En nuestra experiencia, el p504s resultó positivo únicamente en el $2 \%$ de las glándulas prostáticas normales (Fig. 6), con una expresión intracitoplásmica granular más débil y focal por parte de algunas células prostáticas normales pero bizarras, en comparación con las glándulas tumorales ${ }^{21,22,27}$ (Fig. 9). En base a estos hallazgos se ha recomendado que únicamente se considere como positiva la tinción con AMACR en glándulas morfológicamente atípicas cuando esa tinción sea intensa y circunferencial, o significativamente más intensa que el fondo de glándulas benignas ${ }^{21,22,27}$. 
Tabla 2. Sensibilidad de a-metilacil coenzima A racemasa en la detección de cancer de próstata: resumen de los estudios publicados

\begin{tabular}{|c|c|c|c|c|}
\hline Autor & $\begin{array}{l}\text { Número } \\
\text { de casos }\end{array}$ & Tipo de especimen & Anticuerpo & Sensibilidad \\
\hline Jiang 31 & 137 & BA, 58; P, 77; RTUP, 18 & Monoclonal & $100 \%$ \\
\hline Jiang 32 & 73 & BA con focos $<1 \mathrm{~mm}$ & Monoclonal & $95 \%$ \\
\hline Beach $^{41}$ & 186 & $\mathrm{BA}$ & Monoclonal & $82 \%$ \\
\hline Luo $^{34}$ & 142 & MAT de P & Desc & $88 \%$ \\
\hline Rubin $^{30}$ & 94 & BA. Consecutiva & Policlonal & $97 \%$ \\
\hline Leav $^{33}$ & 25 & Carcinoma de la zona transicional & Desc & $100 \%$ \\
\hline Magi-Galluzzi ${ }^{35}$ & 209 & BA. Focos pequeños $<5 \%$ & Policlonal & $88 \%$ \\
\hline Kunju $^{43}$ & 20 & BA. 6 focos pequeños y 4 glándulas espumosas de cáncer & Monoclonal & $90 \%$ \\
\hline Zhou ${ }^{39}$ & 38 & BA. Glándula espumosa e hiperplásica & $\begin{array}{l}\text { Monoclonal } \\
\text { Policlonal }\end{array}$ & $\begin{array}{l}71 \% \\
65 \%\end{array}$ \\
\hline Zhou $^{38}$ & 215 & BA. Material de referencia & Monoclonal & $82 \%$ \\
\hline Yang $^{44}$ & 48 & Casos postradioterapia & Desc & $100 \%$ \\
\hline Jiang $^{14}$ & 454 & BA, 27 P, 178; RTUP, estudio multicéntrico & Monoclonal & $97 \%$ \\
\hline Farolina ${ }^{45}$ & 23 & Carcinoma atrófico & Desc & $70 \%$ \\
\hline Hameed $^{46}$ & 189 & Comparación con la combinación de P63/AMACR & Monoclonal & $94 \%$ \\
\hline Molinié 21 & 150 & BA, P, RTUP, estudio multicéntrico & Monoclonal & $97 \%$ \\
\hline
\end{tabular}

BA: Biopsia por aguja; Desc: desconocido; P, prostatectomía; RTUP: resección transuretral de próstata; MAT: microarray tisular.

Además, la aplicación de anticuerpos coexistentes frente a las células basales (como el p63) demostró que las glándulas normales con positividad para p504s tuvieron menos tinción de
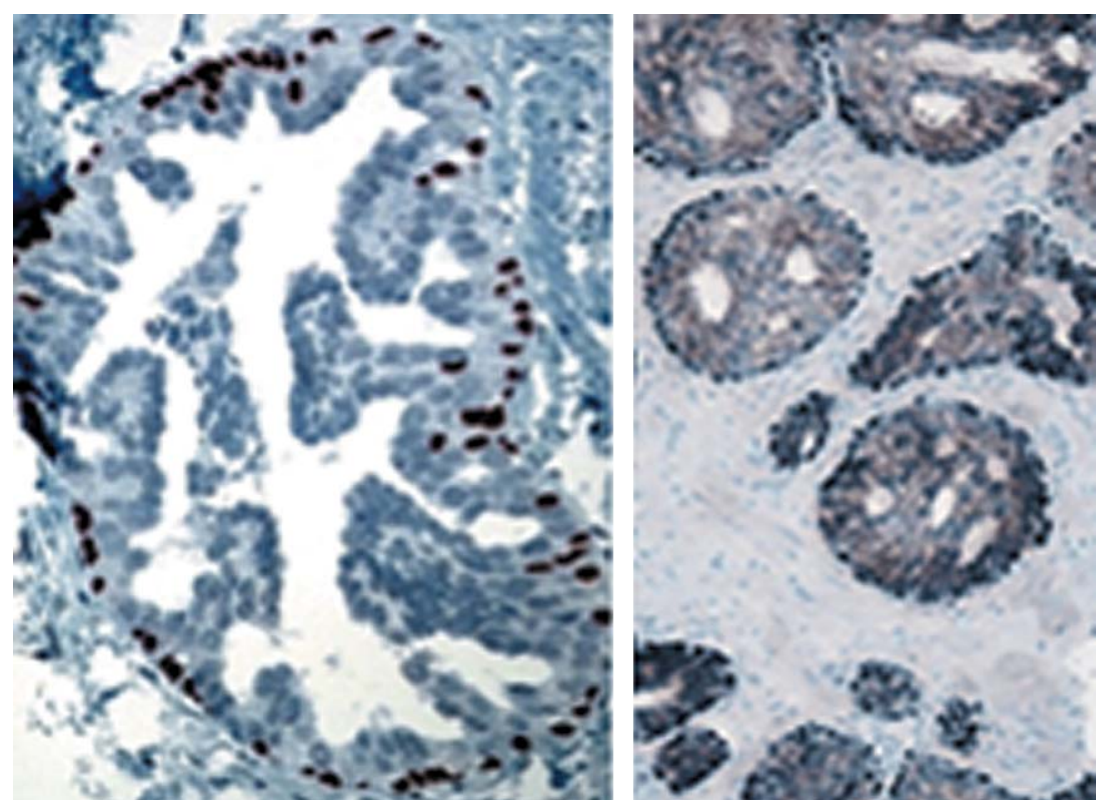

FIGURA 8. P63/P504S en PIN de bajo grado (izquierda) y PIN de alto grado (derecha). células basales que las glándulas normales no positivas para p504s; esas glándulas podrían ser consideradas como afectadas por PIN de bajo grado. En consecuencia, nuestra hipótesis fue que el aumento de expresión de AMACR en algunas glándulas prostáticas normales podría representar un cambio preneoplásico temprano, y que podría reflejar una regulación al alza de los patrones metabólicos de las glándulas prostáticas durante el proceso de la carcinogénesis ${ }^{8}$. El aumento de expresión de AMACR confirmó la regulación al alza de los patrones metabólicos de las glándulas normales $\mathrm{y}$, por esa razón, el p504s puede ser considerado un marcador útil de transformación neoplásica en la glándula prostática ${ }^{21,22,27,37}$.

De este modo, confirmamos la ausencia de expresión de p504s en casos de atrofia, hiperplasia post- 

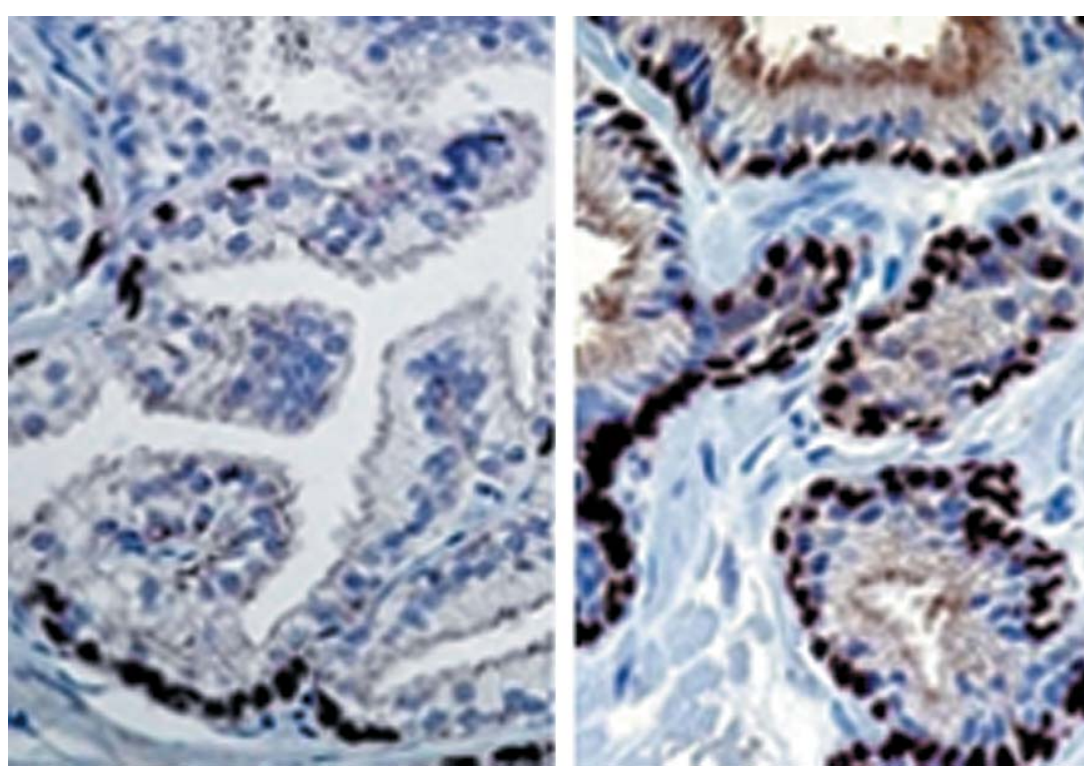

FIGURA 9. P63/P504S en glándulas normales.

un fenotipo con un marcador de células basales negativo (CK903, CK5/6 o p63), y positivo para p504s debe sugerir malignidad ${ }^{38}$. Esta asociación de dos tipos de marcadores ha sido señalada por varios autores.

Desde el momento en que ningún marcador de células basales es capaz de teñir todos los acini benignos, la utilización de dos o más marcadores en la forma de una mezcla de anticuerpos o panel puede resultar ventajosa, particularmente en la evaluación de focos atípicos de pequeño tamaño. Zhou et al. han recomendado la utilización de una mezcla de anticuerpos para células basales que incluye p63 y 34ßE12; la razón es que

atrofia (o atrofia parcial), metaplasia transicional e hiperplasia de células basales ${ }^{21,22,27}$. Estos resultados son marcadamente diferentes de los alcanzados por Herawi et al. ${ }^{47}$ Estos autores identificaron tinción con AMACR en el $79 \%$ de los casos de atrofia parcial y en el 67\% de los focos de microacinos agrupados, dos entidades que remedan al cáncer de próstata, mientras que el HMWCK resultó negativo en el $13 \%$ y en el 17\% de sus casos, respectivamente ${ }^{47}$. Estas diferencias podrían ser explicadas por el hecho de que los casos fueron teñidos en diferentes instituciones, con diferentes anticuerpos y técnicas. Además, en sus comunicaciones no proporcionaron sus resultados de la tinción doble con HMWCK/p504s ${ }^{47}$. En nuestra experiencia en hiperplasia adenomatosa, la alta expresión observada en más del 70\% de las células prostáticas confirmó los resultados de Yang et al. ${ }^{37}$

Desde el punto de vista del diagnóstico, es importante reconocer que la tinción aislada para AMACR no es probatoria de malignidad ${ }^{38}$. En lesiones prostáticas benignas, como la atrofia parcial, la adenosis, y en los tejidos prostáticos con escaso estroma por hiperdesarrollo glandular, se produce tinción focal con p504s. En general, la tinción es más débil que en el carcinoma de próstata, y creemos que únicamente estos marcadores tienen como diana diferentes antígenos dentro de la misma célula, y, por tanto, pueden resultar sensibles a diferentes factores técnicos ${ }^{29}$. En comparación con la utilización de los marcadores en un panel, la combinación de anticuerpos resultaría más económica, y particularmente útil para el estudio de lesiones mínimas que podrían no estar representadas en secciones seriadas de niveles más profundos ${ }^{29}$. Existen combinaciones de anticuerpos pre-elaboradas disponibles comercialmente, pero las concentraciones de los anticuerpos individuales no pueden ser ajustadas para compensar las variaciones locales en el procesamiento de las preparaciones tisulares y en la metodología de tinción. La mayoría de los autores que han comunicado la existencia de tinción $34 \beta \mathrm{E} 12$ o CK 5/6 con p504s se vieron obligados a utilizar una reacción de doble color con avidina-biotina y sustratos de fosfatasa alcalina, lo que no constituye un procedimiento rutinario. Así, la doble inmunotinción con una combinación de anticuerpos p63/P504S se consigue con un único cromógeno aplicado junto a una mezcla de anticuerpos secundarios (inmunoglobulinas anti-ratón y anti-conejo, respectivamente). Más recientemente, se han empleado con éxito combinaciones de AMACR con p63 y/o $34 \beta \mathrm{E} 12^{15}$. En nuestra experiencia, hemos empleado la combinación de anticuerpos frente a 
p63/AMACR prediluida disponible comercialmente. Utilizando esa combinación obtuvimos un patrón de inmunotinción mediante un anticuerpo monoclonal de ratón, encontrándose la inmunorreactividad frente a p63 localizada en el núcleo de las células basales; el anticuerpo monoclonal de conejo anti-AMACR (el p504S) resultó positivo en el citoplasma y en la luz de las células y glándulas prostáticas, respectivamente. La positividad con p63 es más fácil de identificar con un único procedimiento de tinción del complejo avidina-biotina que con CK903 o CK5/6, anticuerpos que dan lugar a tinción citoplásmica ${ }^{5}$.

La asociación de p504s y p63 constituye un marcador útil de transformación neoplásica de la glándula prostática, y debe de ser propuesto como procedimiento auxiliar al examen de la morfología histológica. Esa combinación representa un potencial marcador de las células tumorales prostáticas en el contexto diagnóstico adecuado, con una sensibilidad que se acerca al 97\% y una especificidad próxima al $100 \%{ }^{21}$. En uno de nuestros estudios, el empleo de esa combinación de marcadores permitió clasificar el 89,4\% de las lesiones ambiguas; el diagnóstico final fue de lesión benigna ( $25 \%$ de los casos), foco de cáncer mínimo $(47,11 \%)$, PIN de alto grado $(14,4 \%)$ e hiperplasia adenomatosa atipica (2.8\%). El rendimiento alcanzado con esa combinación de marcadores fue superior al alcanzado con la inmunotinción mediante p504s como marcador único ${ }^{21}$ (Fig. 7).

Sin embargo, los anatomopatólogos deben recordar que la amplia expresión de la tinción con p504s comunicada en las series publicadas podría traducir diferencias en los tipos de anticuerpo primario (monoclonal o policlonal), en las concentraciones de los anticuerpos, en la solución de fijación utilizada, así como en el protocolo de recuperación de cada centro ${ }^{23}$. Una fuente adicional de variabilidad en los resultados de sensibilidad y especificidad para el p504s parece relacionada con los diferentes abordajes adoptados para la interpretación de la inmunotinción ${ }^{23,47}$. Como la mayoría de los autores, nosotros recomendamos que la tinción con p504s se considere positiva en las glándulas ambiguas, únicamente si es intensa y circunferencial, o significativamente más intensa que la del fondo de glándulas benignas ${ }^{23,50}$. No obstante, algunos autores también consideran como positiva una intensidad débil, lo que podría justificar, al menos en parte, las positividades detectadas en glándulas normales ${ }^{41}$. El grupo del Johns Hopkins interpreta la positividad débil de p504s en las glándulas ambiguas como positiva, únicamente si las glándulas benignas son completamente negativas; de modo similar, consideran negativa una tinción de intensidad moderada si las glándulas normales presentan un nivel moderado de positividad para $\mathrm{p} 504 \mathrm{~s}^{23}$. La mayor parte de esa dificultad puede ser explicada por el hecho de que la inmunotinción con p504s es una tinción que proporciona resultados cuantitativos, mientras que la tinción con marcadores de células basales proporciona resultados cualitativos. Con los marcadores de células basales existe un límite bien definido entre glándulas benignas y malignas (las células basales se encuentran casi siempre ausentes en las glándulas malignas) mientras que no existe un nivel definido para la tinción con AMACR. El análisis mediante Western-blot ha revelado que los cánceres de próstata expresan hasta 36 veces más AMACR que el tejido benigno ${ }^{34,51}$. Así, la tinción de la próstata con p504s representa una variable continua desde las glándulas benignas a las malignas, y la débil positividad observada en las glándulas benignas representa una auténtica positividad, más que una reacción falsamente positiva, y puede intensificarse utilizando un procedimiento de inmunotinción más sensible (Fig. 9).

Por todas las razones antes mencionadas, consideramos que la inmunotinción de p504s debe de ser interpretada junto con los resultados de inmunotinción de células basales. En nuestra experiencia, este modo de interpretación parece más relevante que el establecimiento de niveles arbitrarios como puntos de corte entre casos positivos y negativos (Fig. 10). Adicionalmente, el procesamiento con inmunotinción automática permite llevar a cabo el procedimiento de inmunotinción con incubación del anticuerpo primario en dos pasos y un anticuerpo secundario mixto anti-ratón y anti-conejo, utilizando el mismo procedimiento de tinción con avidina-biotina durante el mismo proceso. 


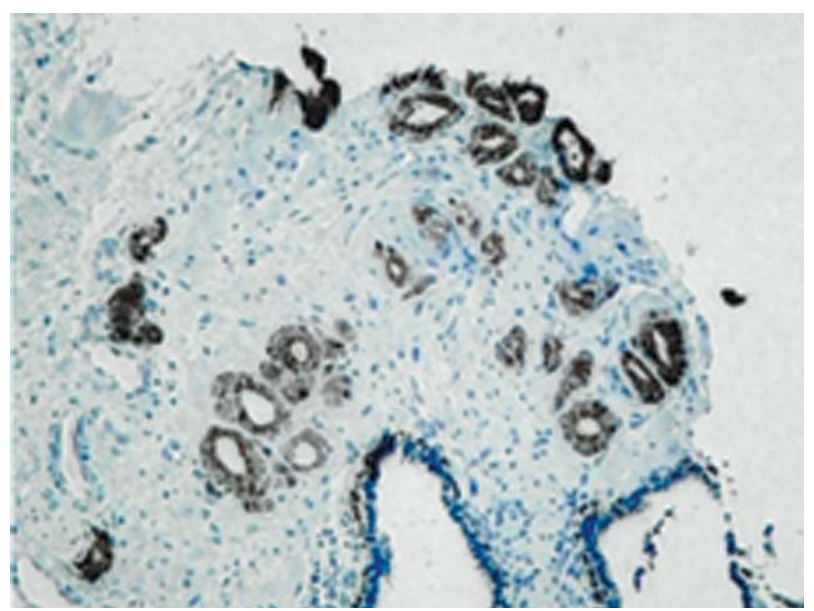

FIGURA 10. P63/P504S en un pequeño foco de carcinoma.

Esta rutina reduce considerablemente el tiempo de procesamiento y permite la detección mediante un procedimiento rutinario. Esta técnica de acoplamiento de dos anticuerpos al mismo tiempo redujo el número de cortes necesarios, el tiempo de técnica $\mathrm{y}$, en caso de ambigüedad, redujo el porcentaje de interpretaciones no concluyentes y de biopsias adicionales. Tal y como Hemmed et al. demostraron, nosotros comprobamos que el uso de combinaciones comerciales de métodos de tinción constituye un procedimiento de tinción rutinaria fácilmente disponible que tendrá un impacto en la capacidad de reconocer con claridad el cáncer de próstata ${ }^{46}$ (Fig. 11).

\section{Diagnóstico diferencial entre carcinoma de próstata y carcinoma urotelial pobremente diferenciado}

La distinción del cáncer urotelial de alto grado del cáncer de próstata pobremente diferenciado en muestras de resección transuretral es un problema relativamente común. $\mathrm{El}$ antecedente de un tumor urotelial o de un carcinoma urotelial in situ podría favorecer la aparición de un carcino-

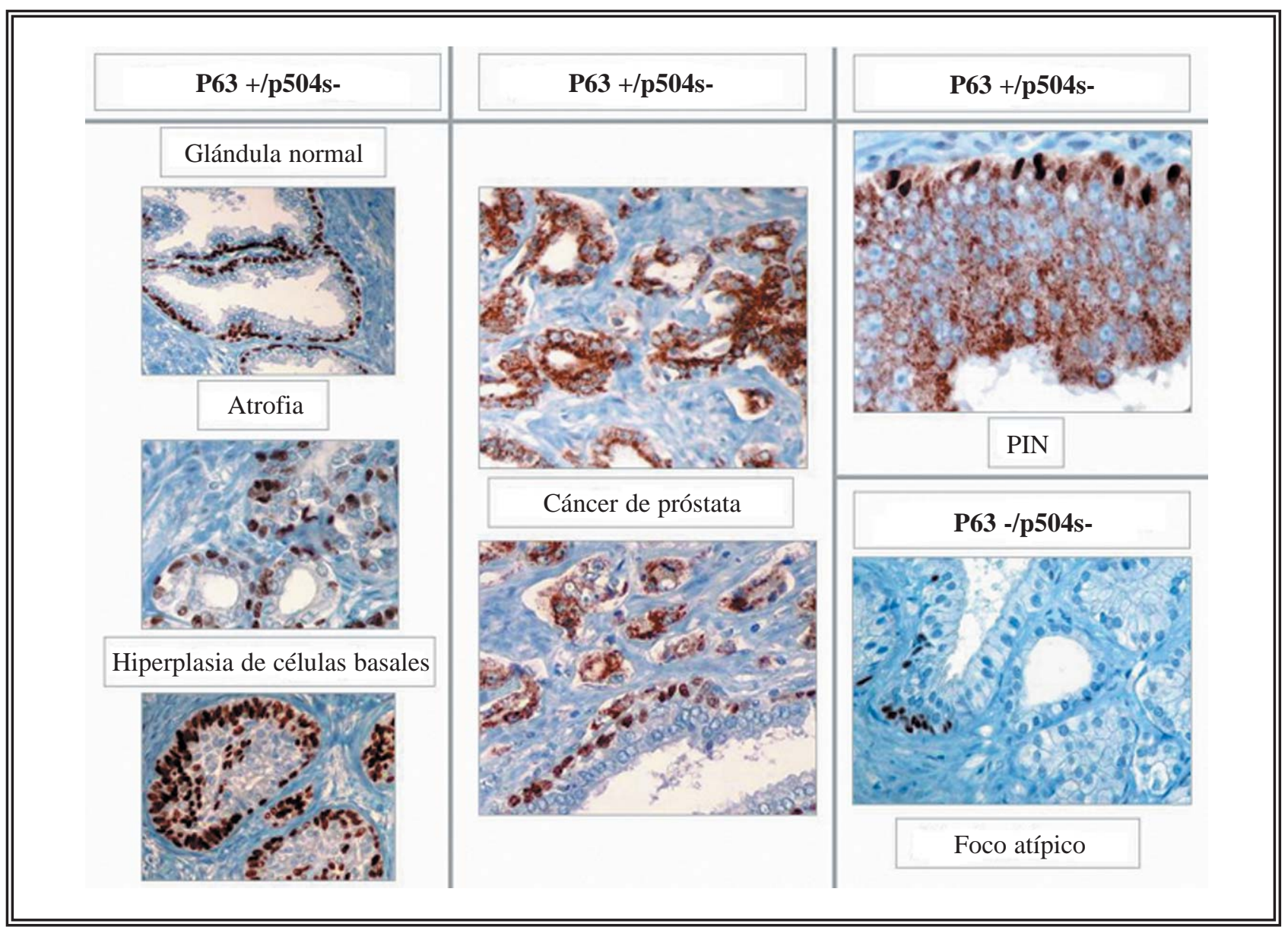

FIGURA 11. Diferentes patrones de inmunotinción con p63/p504s. 
ma urotelial de alto grado, pero la posibilidad de un cáncer de próstata sincrónico debería de ser excluida dado que ambos tumores aparecen en el varón anciano. En casos morfológicamente equívocos habitualmente se utiliza la determinación inmunohistoquímica de PSA y PSAP para confirmar el origen prostático del tumor. Sin embargo, los muestras de cáncer de próstata pobremente diferenciado resultan negativos para PSA y PSAP hasta en el 27 y 19\% de los casos, respectivamente ${ }^{52}$. En esos casos, la adición de anticuerpos frente a CK7, CK20, 34ßE12 y p63 resulta de utilidad $^{50}$. El CK7 se expresa en el $82-100 \%$ de los casos de carcinoma urotelial, en tanto el CK20 lo hace en el 22-100\% de las ocasiones. Por el contrario, esos marcadores no se detectan cuando el recuento de células tumorales es inferior al 5\%, ni en el cáncer de próstata ${ }^{23}$. Una positividad significativa para PSA y/o PSAP asociada con una inmunorreacción con HMWCK muy focal o negativa es suficiente para establecer un diagnóstico de cáncer de próstata ${ }^{52,53}$. Por otro lado, la positividad difusa para HMWCK asociada con una inmunorreacción negativa para PSA y PSAP, son suficientes para establecer un diagnóstico de carcinoma urotelial en el adecuado contexto clínico. En nuestra experiencia, p63 y CK7 son siempre positivos en los tumores uroteliales, incluso en carcinomas uroteliales pobremente diferenciados. La utilización de AMACR no tiene utilidad porque los tumores pobremente diferenciados (prostáticos y uroteliales) pueden expresar ese anticuerpo $^{3}$ (Fig. 12). Otros marcadores uroteliales sensibles, como el antígeno carcinoembrionario (CEA), la trombomodulina y la uroplaquina III, pueden utilizarse para el diagnóstico de carcinoma urotelial ${ }^{23}$. Algunos autores recomiendan la utilización de un panel de inmunotinción incluyendo PSA y PSAP para la identificación de cáncer de próstata, y de trombomodulina y $34 \beta \mathrm{E} 12$ para excluir el carcinoma urotelial ${ }^{3}$. En caso de un resultado no informativo, puede ensayarse una segun- da línea diagnóstica con p63, uroplaquina III, Leu 7, CK5/6, p53, CK7 y CK 20. Esta segunda batería de anticuerpos es menos específica que el panel inicial ${ }^{3}$ (Tabla 3 ).

Tabla 3. Expresión de marcadores de carcinoma urotelial y prostático según Hammed et al. ${ }^{3}$

\begin{tabular}{lcc}
\hline & $\begin{array}{c}\text { Carcinoma } \\
\text { de próstata \% }\end{array}$ & $\begin{array}{c}\text { Carcinoma } \\
\text { urotelial \% }\end{array}$ \\
\hline PSA & $94-100$ & 0 \\
PSAP & $89-100$ & 0 \\
Trombomodulina & 0 & $49-91$ \\
34ßE12 & $0-10$ & $65-100$ \\
p63 & $0-3$ & $62-75$ \\
CK 5/6 & 0 & $62-75$ \\
Uroplaquina III & 0 & $57-60$ \\
CEA Monoclonal & $0-12$ & 41 \\
Leu 7 & 94 & 17 \\
CK 7 & $0-12$ & $83-100$ \\
CK 20 & $0-29$ & $15-94$ \\
p53 & 3 & 33 \\
\hline
\end{tabular}

\section{Diagnóstico diferencial del cáncer de} próstata frente a carcinomas no prostáticos

La identificación del origen prostático del carcinoma metastático es importante en tanto el cáncer de próstata metastático con frecuencia responde al tratamiento hormonal, y se suele asociar a supervivencias más prolongadas que

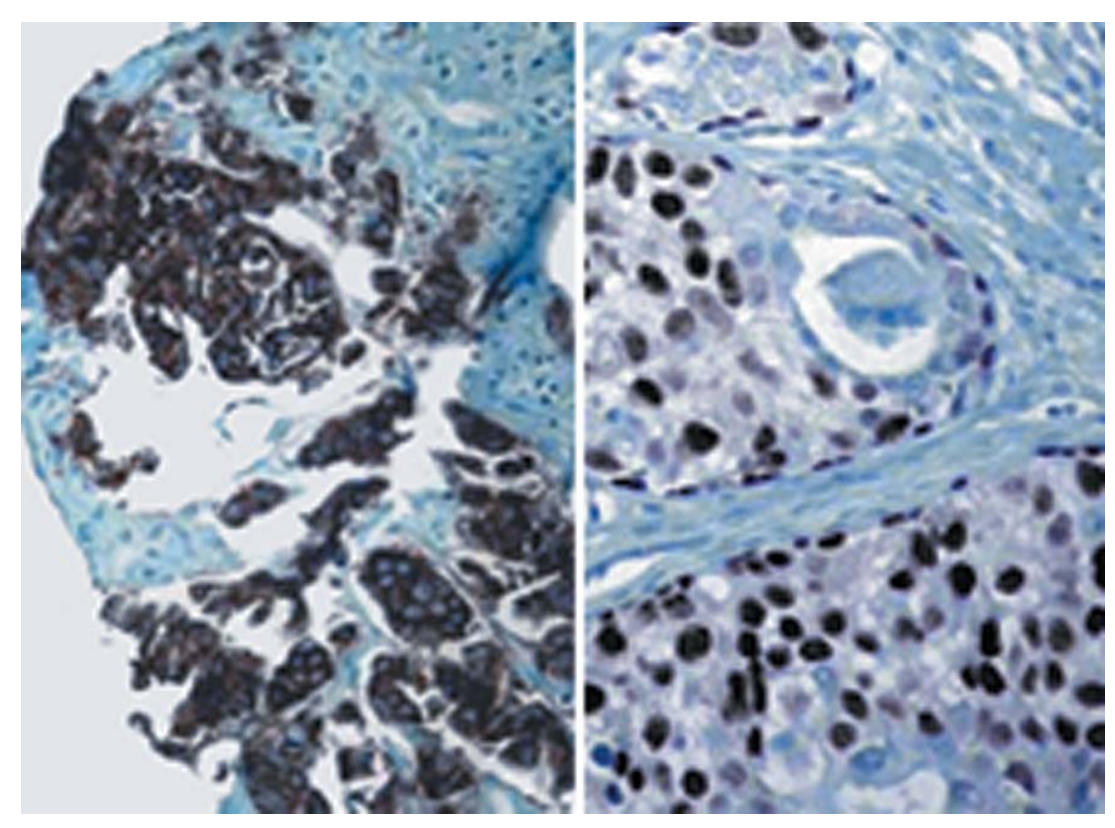

FIGURA 12. Carcinoma urotelial con invasión prostática: positividad nuclear en las células basales con p63 y CK 7. 
otros tumores metastáticos. La elección del marcador inmunohistoquímico utilizado en la distinción del cáncer de próstata de los carcinomas no prostáticos depende del diagnóstico diferencial clinicopatológico. En las localizaciones metastáticos, donde el diagnóstico diferencial incluye una variedad de tumores no prostáticos tales como el cáncer de pulmón, el cáncer de vejiga o del tracto gastrointestinal, los marcadores prostáticos PSA y fosfatasa ácida prostática (FAP), se utilizan asociados a otros marcadores como el CEA y a otros marcadores de cáncer de próstata más modernos (P501s y PSMA) ${ }^{3}$ (Figs. 13 y 14). Varios
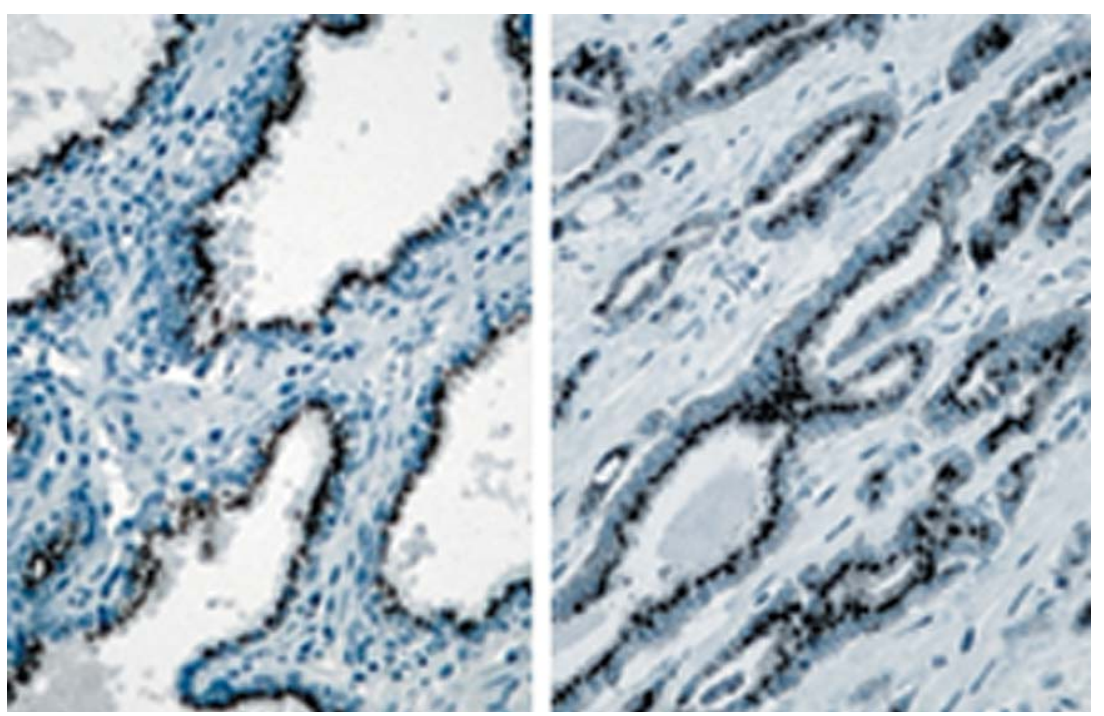

FIGURA 13. P501s en próstata normal (izquierda) y en carcinoma de próstata (derecha).
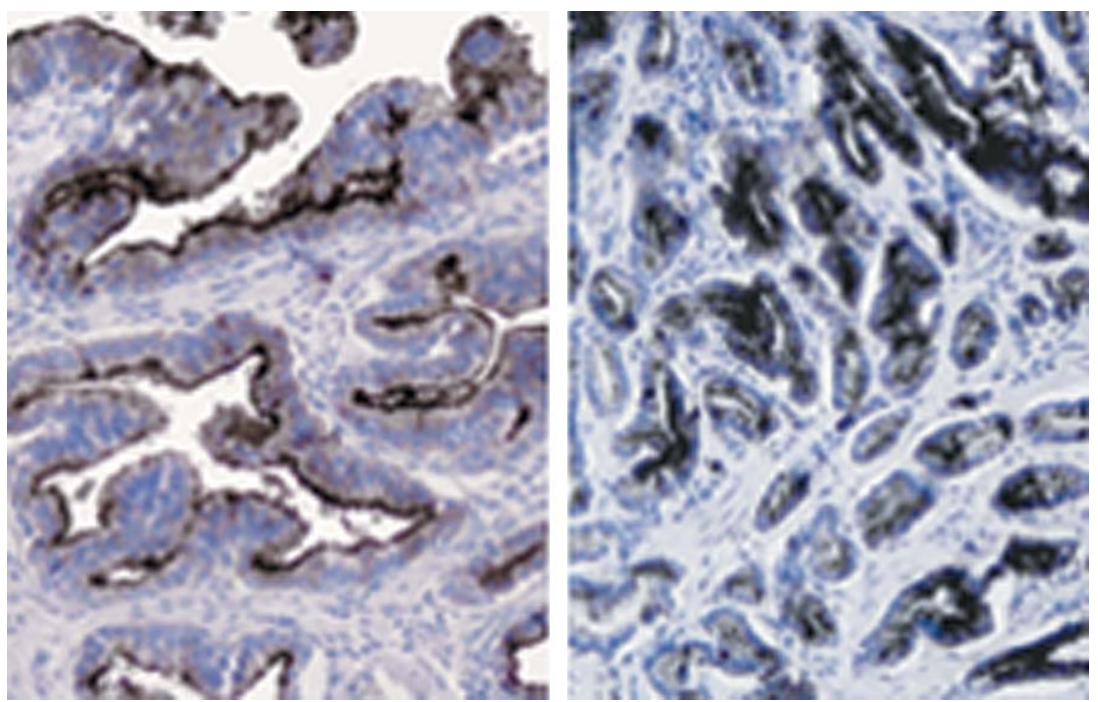

FIGURA 14. PSAM en próstata normal (izquierda) y en el carcinoma de prósta ta (derecha). estudios han probado la positividad de la inmunorreactividad en el 96-100\% de los casos de carcinoma de próstata bien diferenciado ${ }^{3}$. En el carcinoma de próstata pobremente diferenciado se observa inmunorreactividad frente a PAP y PSA en 5-35\% de los casos. Otros estudios han probado que el anticuerpo policlonal frente al PSA es significativamente más sensible que el anticuerpo monoclonal. El patrón de Gleason 5 sugiere que el anti-PSA policlonal debería de ser considerado como el marcador de elección para demostrar la expresión de PSA en el cáncer de próstata pobremente diferenciado. Sin embargo, existen evidencias de la expresión inmunohistoquímica de PSA y/o PSAP en una variedad de tejidos y tumores no prostáticos (Tablas 4 y 5).

\section{CONCLUSIÓN Y PERSPECTIVAS}

El PSA y el PSAP son marcadores inmunohistoquímicos bien establecidos para la determinación del origen prostático del carcinoma pobremente diferenciado. La inclusión de ciertos refinamientos para asegurar el control de calidad de los análisis debería de asegurar una mayor sensibilidad para ambos marcadores en este escenario clínico.

La reciente introducción de nuevos marcadores como el p63 y la AMACR representa un avance significativo en el estudio inmunohistoquímico del cáncer de próstata: la AMACR es el primer marcador inmunohistoquímico que muestra especificidad por el cáncer de próstata en comparación con el tejido prostático benigno, y podría ser utilizado en el diagnóstico y en la evaluación terapéutica (Figs. 15 y 16). El anticuerpo frente a AMACR fue desarrollado frente a un producto proteico citoplásmico de un gen identificado como sobreexpresado en el cáncer de próstata. Es probable que este tipo de abordaje 
Tabla 4. Tejidos no prostáticos y tumores que expresan PSA

\begin{tabular}{l}
\hline No neoplásicos \\
Vejiga: cistitis quística y glandular \\
Glándulas periuretrales y perianales \\
Remanentes uracales \\
Glándulas de Cowper \\
Vesículas seminales \\
\hline Neoplásicos \\
Mama: adenocarcinoma \\
Neoplasias de las glándulas salivares \\
Vejiga: \\
Adenocarcinoma \\
Adenocarcinoma de las glándulas parauretrales de \\
Skene Glándulas parauretrales \\
Colon: adenocarcinoma \\
Melanoma maligno \\
Páncreas: carcinoma de células acinares
\end{tabular}

Tabla 5. Tejidos no prostáticos y tumores que expresan PSAP

\begin{tabular}{l} 
No neoplásicos \\
Vejiga: cistitis quística y glandular \\
Glándulas periuretrales y perianales \\
Vesículas seminales \\
\hline Neoplásicos \\
Mama: adenocarcinoma \\
Neoplasias de las glándulas salivares \\
Vejiga: \\
Adenocarcinoma \\
Adenocarcinoma de las glándulas parauretrales de \\
Skene glándulas parauretrales \\
Colon: adenocarcinoma \\
Melanoma maligno \\
Páncreas: \\
Carcinoma de células acinares \\
Tumor de los islotes celulares \\
Tumores carcinoides \\
\hline
\end{tabular}

basado en el análisis genómico proporcione nuevos marcadores inmunohistoquímicos de importancia clínica en el futuro. El anticuerpo monoclonal frente a AMACR p504S es también uno de la nueva generación de anticuerpos monoclonales de conejo disponibles comercialmente que no son inmunogénicos en ratón.

Dada la notable variabilidad entre laboratorios en las determinaciones de inmunorreactividad AMACR, la utilización del p63 como marcador negativo de cáncer de próstata representa un importante avance para el diagnóstico diferencial de las proliferaciones acinares glandulares de pequeñas dimensiones, y su diferenciación del cáncer invasivo y del PIN de alto grado.

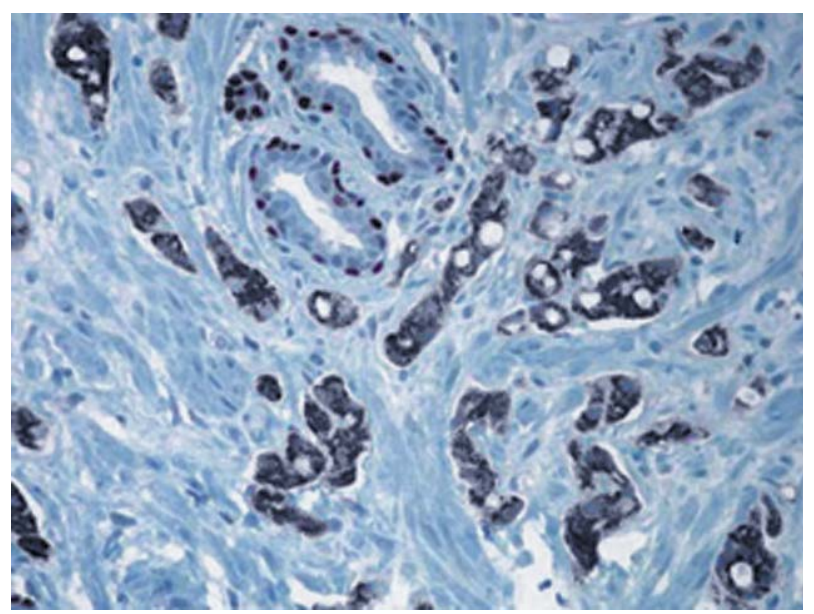

FIGURA 16. Carcinoma de próstata tratado con agonista de la LHRH. Tras tinción con p504s. Suma de Gleason $6(3+3)$.

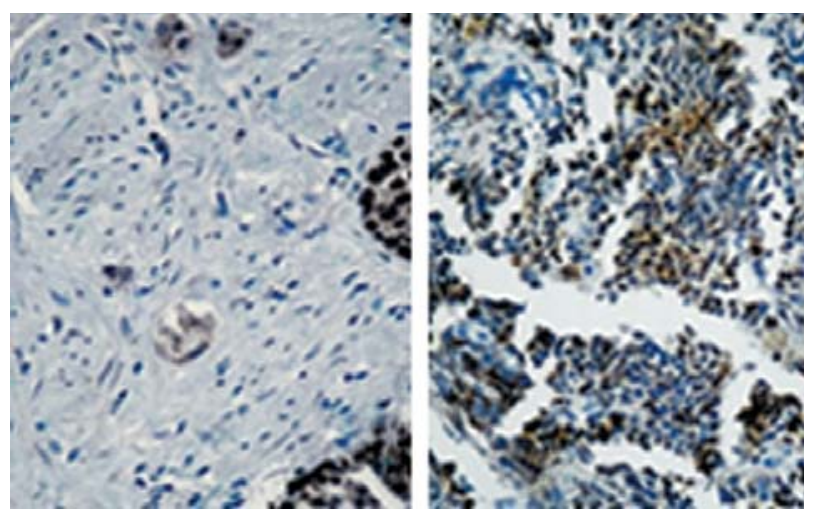

FIGURA 15. P63/P504S en carcinoma tratado con LHRH (izquierda) y en carcinoma de célula pequeña (derecha).

\section{REFERENCIAS}

1. Epstein JI. Diagnosis and reporting of limited adenocarcinoma of the prostate on needle biopsy. Mod Pathol. 2004; 17(3):307-315.

2. Evans AJ. Alpha-methylacyl CoA racemase (P504S): overview and potential uses in diagnostic pathology as applied to prostate needle biopsies. J Clin Pathol. 2003;56(12): 892-897.

3. Hameed O, Humphrey PA. Immunohistochemistry in diagnostic surgical pathology of the prostate. Semin Diagn Pathol. 2005;22(1):88-104.

4. Iczkowski KA, Bostwick DG. Criteria for biopsy diagnosis of minimal volume prostatic adenocarcinoma: analytic comparison with nondiagnostic but suspicious atypical small acinar proliferation. Arch Pathol Lab Med. 2000;124 (1):98-107.

5. Srigley JR: Benign mimickers of prostatic adenocarcinoma. Mod Pathol. 2004; 17(3):328-348.

6. Molinie V. Minute focus, suspected focus and high-grade prostatic intraepithelial neoplasia. What is the significance? What are the consequences?. Prog Urol. 2004;14(1 Suppl): 2-6. 
7. Thorson P, Humphrey PA. Minimal adenocarcinoma in prostate needle biopsy tissue. Am J Clin Pathol. 2000;114 (6):896-909.

8. Davis LD, Zhang W, Merseburger A, Young D, Xu L, Rhim JS et al. p63 expression profile in normal and malignant prostate epithelial cells. Anticancer Res. 2002; 22(6c): 3819-3825.

9. Helpap B, Kollermann J, Oehler U. Limiting the diagnosis of atypical small glandular proliferations in needle biopsies of the prostate by the use of immunohistochemistry. J Pathol. 2001;193(3):350-353.

10. Parsons JK, Gage WR, Nelson WG, De Marzo AM. p63 protein expression is rare in prostate adenocarcinoma: implications for cancer diagnosis and carcinogenesis. Urology. 2001;58(4):619-624.

11. Shah RB, Kunju LP, Shen R, LeBlanc M, Zhou M, Rubin MA. Usefulness of basal cell cocktail (34betaE12 + p63) in the diagnosis of atypical prostate glandular proliferations. Am J Clin Pathol. 2004; 122(4):517-523.

12. Carella R, Deleonardi G, D'Errico A, Salerno A, EgarterVigl E, Seebacher C et al. Immunohistochemical panels for differentiating epithelial malignant mesothelioma from lung adenocarcinoma: a study with logistic regression analysis. Am J Surg Pathol. 2001;25(1):43-50.

13. Gown AM, Vogel AM. Monoclonal antibodies to human intermediate filament proteins. III. Analysis of tumors. Am J Clin Pathol. 1985; 84(4):413-424.

14. Jiang Z, Iczkowski KA, Woda BA, Tretiakova M, Yang XJ. P504S immunostaining boosts diagnostic resolution of "suspicious" foci in prostatic needle biopsy specimens. Am J Clin Pathol. 2004;121(1):99-107.

15. Jiang Z, Li C, Fischer A, Dresser K, Woda BA. Using an AMACR (P504S)/34betaE12/p63 cocktail for the detection of small focal prostate carcinoma in needle biopsy specimens. Am J Clin Pathol. 2005; 123(2):231-236.

16. Hedrick L, Epstein JI. Use of keratin 93 as an adjunct in the diagnosis of prostate carcinoma. Am J Surg Pathol. 1989;13(5):389-396.

17. Yang XJ, Lecksell K, Gaudin P, Epstein JI. Rare expression of high-molecular-weight cytokeratin in adenocarcinoma of the prostate gland: a study of 100 cases of metastatic and locally advanced prostate cancer. Am J Surg Pathol. 1999;23(2):147-152.

18. Abrahams NA, Ormsby AH, Brainard J. Validation of cytokeratin 5/6 as an effective substitute for keratin 903 in the differentiation of benign from malignant glands in prostate needle biopsies. Histopathology. 2002;41(1):35-41.

19. Chu PG, Weiss LM. Expression of cytokeratin 5/6 in epithelial neoplasms: an immunohistochemical study of 509 cases. Mod Pathol. 2002;15(1):6-10.

20. Chu PG, Weiss LM. Keratin expression in human tissues and neoplasms. Histopathology. 2002;40(5):403-39.

21. Molinie V, Fromont G, Sibony M, Vieillefond A, Vassiliu V Cochand-Priollet B et al. Diagnostic utility of a p63/alphamethyl-CoA-racemase (p504s) cocktail in atypical foci in the prostate. Mod Pathol. 2004;17(10):1180-1190.

22. Molinie V, Herve JM, Lebret T, Lugagne-Delpon PM Saporta F, Yonneau L et al. Value of the antibody cocktail anti p63 + anti p504s for the diagnosis of prostatic cancer. Ann Pathol. 2004;24(1):6-16.

23. Varma M, Jasani B. Diagnostic utility of immunohistochemistry in morphologically difficult prostate cancer: review of current literature. Histopathology. 2005;47(1):1-16.

24. Yang A, McKeon F. P63 and P73: P53 mimics, menaces and more. Nat Rev Mol Cell Biol. 2000;1(3):199-207.
25. Signoretti S, Waltregny D, Dilks J, Isaac B, Lin D, Garraway $\mathrm{L}$ et al. p63 is a prostate basal cell marker and is required for prostate development. Am J Pathol. 2000:157 (6): 1769-1775.

26. Weinstein MH, Signoretti S, Loda M. Diagnostic utility of immunohistochemical staining for p63, a sensitive marker of prostatic basal cells. Mod Pathol. 2002;15(12):13021308.

27. Molinie V, Herve JM, Lugagne PM, Baglin AC. P63 and p504s cocktail is useful in ambiguous lesions of the prostate. Histopathology. 2004;44(4):403-404.

28. Shah RB, Zhou M, LeBlanc M, Snyder M, Rubin MA. Comparison of the basal cell-specific markers, 34betaE12 and p63, in the diagnosis of prostate cancer. Am J Surg Pathol. 2002;26(9):1161-1168.

29. Zhou M, Shah R, Shen R, Rubin MA. Basal cell cocktail (34betaE12 + p63) improves the detection of prostate basal cells. Am J Surg Pathol. 2003;27(3):365-371.

30. Rubin MA, Zhou M, Dhanasekaran SM, Varambally S, Barrette TR, Sanda MG et al. Alpha-Methylacyl coenzyme A racemase as a tissue biomarker for prostate cancer. Jama. 2002;287(13):1662-1670.

31. Jiang Z, Woda BA, Rock KL, Xu Y, Savas L, Khan A et al. P504S: a new molecular marker for the detection of prostate carcinoma. Am J Surg Pathol, 2001;25(11):13971404.

32. Jiang Z, Wu CL, Woda BA, Xu Y, Savas L, Khan A et al. P504S/alpha-methylacyl-CoA racemase: a useful marker for diagnosis of small foci of prostatic carcinoma on needle biopsy. Am J Surg Pathol. 2002;26(9):1169-1174.

33. Leav I, McNeal JE, Ho SM, Jiang Z. Alpha-methylacyl-CoA racemase (P504S) expression in evolving carcinomas within benign prostatic hyperplasia and in cancers of the transition zone. Hum Pathol. 2003;34(3):228-233.

34. Luo J, Zha S, Gage WR, Dunn TA, Hicks JL, Bennett CJ et al. Alpha-methylacyl-CoA racemase: a new molecular marker for prostate cancer. Cancer Res. 2002;62(8):2220-2226.

35. Magi-Galluzzi C, Luo J, Isaacs WB, Hicks JL, de Marzo AM, Epstein JI. Alpha-methylacyl-CoA racemase: a variably sensitive immunohistochemical marker for the diagnosis of small prostate cancer foci on needle biopsy. Am J Surg Pathol. 2003;27(8):1128-1133.

36. Sanderson SO, Sebo TJ, Murphy LM, Neumann R, Slezak J, Cheville JC. An analysis of the p63/alpha-methylacyl coenzyme A racemase immunohistochemical cocktail stain in prostate needle biopsy specimens and tissue microarrays. Am J Clin Pathol, 2004;121(2):220-225.

37. Yang $\mathrm{XJ}$, Wu CL, Woda BA, Dresser K, Tretiakova M, Fanger GR et al. Expression of alpha-Methylacyl-CoA racemase (P504S) in atypical adenomatous hyperplasia of the prostate. Am J Surg Pathol. 2002;26(7):921-925.

38. Zhou M, Aydin H, Kanane H, Epstein JI. How often does alpha-methylacyl-CoA-racemase contribute to resolving an atypical diagnosis on prostate needle biopsy beyond that provided by basal cell markers?. Am J Surg Pathol. 2004;28(2):239-243.

39. Zhou M, Jiang Z, Epstein JI. Expression and diagnostic utility of alpha-methylacyl-CoA-racemase (P504S) in foamy gland and pseudohyperplastic prostate cancer. Am J Surg Pathol. 2003;27(6):772-778.

40. Xu J, Stolk JA, Zhang X, Silva SJ, Houghton RL, Matsumura $\mathrm{M}$ et al. Identification of differentially expressed genes in human prostate cancer using subtraction and microarray. Cancer Res. 2000;60(6):1677-1682. 
41. Beach R, Gown AM, De Peralta-Venturina MN, Folpe AL, Yaziji H, Salles PG et al. P504S immunohistochemical detection in 405 prostatic specimens including 37618 gauge needle biopsies. Am J Surg Pathol. 2002;26(12): 1588-1596.

42. Schostak M KH, Köllermann J, Schrader M, Miller K. Quantitative real-time RT-PCR for AMACR distinguishes prostate cancer with High specificity from benign lesions. J Urol. 2005; 173:531S (Abstract).

43. Kunju LP, Rubin MA, Chinnaiyan AM, Shah RB. Diagnostic usefulness of monoclonal antibody P504S in the workup of atypical prostatic glandular proliferations. Am J Clin Pathol. 2003; 120(5):737-745.

44. Yang XJ, Laven B, Tretiakova M, Blute RD Jr, Woda BA, Steinberg GD et al. Detection of alpha-methylacyl-coenzyme A racemase in postradiation prostatic adenocarcinoma. Urology. 2003;62(2):282-286.

45. Farinola MA, Epstein JI. Utility of immunohistochemistry for alpha-methylacyl-CoA racemase in distinguishing atrophic prostate cancer from benign atrophy. Hum Pathol. 2004;35(10):1272-1278.

46. Hameed O, Sublett J, Humphrey PA. Immunohistochemical stains for p63 and alpha-methylacyl-CoA racemase, versus a cocktail comprising both, in the diagnosis of prostatic carcinoma: a comparison of the immunohistochemical staining of 430 foci in radical prostatectomy and needle biopsy tissues. Am J Surg Pathol. 2005;295):579-587.

47. Herawi M, Parwani AV, Irie J, Epstein JI. Small glandular proliferations on needle biopsies: most common benign mimickers of prostatic adenocarcinoma sent in for expert second opinion. Am J Surg Pathol. 2005;29(7):874-880.
48. Zhou M, Chinnaiyan AM, Kleer CG, Lucas PC, Rubin MA. Alpha-Methylacyl-CoA racemase: a novel tumor marker over-expressed in several human cancers and their precursor lesions. Am J Surg Pathol. 2002;26(7):926-931.

49. Wu CL, Yang XJ, Tretiakova M, Patton KT, Halpern EF, Woda BA et al. Analysis of alpha-methylacyl-CoA racemase (P504S) expression in high-grade prostatic intraepithelial neoplasia. Hum Pathol. 2004;35(8): 1008-1013.

50. Molinie V, Herve JM, Lugagne PM, Yonneau L, Ellard S, Lebret $\mathrm{T}$ et al. Value of new prostate cancer markers: alpha methylacyl CoA racemase (P504S) and p63. Prog Urol. 2005; 15(4):611-615

51. Jiang Z, Woda BA, Wu CL, Yang XJ. Discovery and clinical application of a novel prostate cancer marker: alphamethylacyl CoA racemase (P504S). Am J Clin Pathol. 2004;122(2):275-289.

52. Goldstein NS. Immunophenotypic characterization of 225 prostate adenocarcinomas with intermediate or high Gleason scores. Am J Clin Pathol. 2002; 117:471-417.

53. Varma M, Morgan M, Jasani B, Tamboli P, Amin MB. Polyclonal anti-PSA is more sensitive but less specific than monoclonal anti-PSA: Implications for diagnostic prostatic pathology. Am J Clin Pathol. 2002;118(2):202-207.

Correspondencia autor: Dr. Vincent Molinié Servicio de Patología

Fundación Hôpital Saint Joseph

184 Rue Raymond Losserand, 75014 Paris

Tel.: (33) 144123645

E-mail autor: vmolinie@hpsj.org

Información artículo: Original - Próstata 